\title{
The Vertical Distribution of Marine Macroplankton. XI. Further Observations on Diurnal Changes.
}

By

\author{
F. S. Russell, D.S.C., B.A., \\ Naturalist at the Plymouth Laboratory.
}

With 7 Figures in the Text.

ON June 3rd-4th, 1926, a further series of observations was made on the vertical migrations of plankton animals by means of collections with the 2-metre stramin ring-trawl. Thus, with the observations made on one night in July, 1924 (1), and on two nights in June, 1925 (2), we now have data for four nights.

Since so few observations of this nature have been made at sea it seems desirable that the results obtained on this fourth night should be published.

The collections were made in the same way as on the previous collections and the log, giving full details of conditions at the time of collecting, has been given in a previous publication (3) in which the behaviour of the young fishes is described.

The collections are noteworthy for the very large numbers of animals caught, catches as large as over 120,000 organisms for a ten-minute haul being recorded. Swarms of Calanus finmarchicus and Crab zoeas were chiefly responsible for these high numbers. It is also interesting to record the presence in the catches at night of numbers of small Portunid crabs up to about a size of $4 \mathrm{~mm}$. in carapace breadth. Of thirty-eight specimens examined all were Portunus depurator.* Small Pandalina brevirostris and Crangonids also migrated at night into layers well above the bottom. Many of the animals living in the upper water layers in the daytime were much nearer the surface on the morning of June 4th than they were on the previous afternoon. This is possibly due to the light intensity being cut down by the enormous swarms of Calanus and Crab zoeas present on June 4 th ; it has already been shown that many of the young fishes were affected in the same way (3, p. 833).

On the whole, however, the results are so confirmatory of the other observations that it is unnecessary to deal with the data as fully as in the two previous papers. They are therefore here given only in the form of

\footnotetext{
* I am greatly indebted to Mr. R. Palmer for the identification of these young Portunids.
} 
diagrams for the many species (Figs. 1 to 7 , pp. 776 and 782) and as a Table setting out the complete catches of all organisms (Table I, pp. 783 and 784).

\section{Comparison of Results of Four Series of Collections.}

It is now possible to compare the results of the four series of collections and on pages 771 to 775 are given in summary form the types of behaviour shown by the more important species on the four nights in question, namely July 15-16th, 1924, June 17-18th, and 18-19th, 1925, and June 3-4th, 1926.

It must be realised that for most species we are dealing with a mixed population, composed of individuals of different ages and perhaps sexes ; this point has been emphasised in a recent publication (4) in which the behaviour of Sagitta of different sizes is studied. It must also be borne in mind that, in the method of collecting, the catches from the different depths have not been made simultaneously (see 2, pp. 81 and 82). We cannot hope, therefore, to attempt to draw conclusions on the fundamental factors controlling the behaviour of the animals. The time has now come when a number of simultaneous collections must be made in rapid succession during the hours of changing light intensity at dusk and dawn, and attention must be given to the behaviour of each stage of development of the species caught.

Nevertheless these four series of collections have given us a very good picture of how the larger plankton animals behave as a whole throughout the twenty-four hours in June and July in the waters off Plymouth.

After a careful study of the available data it is evident that whatever be the physical and chemical conditions of the environment that control the behaviour of the animals and provide the necessary stimuli, there are two factors inherent in the animals themselves which are largely responsible for the type of distribution shown by any species during the night, namely :-

1. The depth at which the animal has been living during the previous daylight.

2. The speed at which the animal is capable of swimming upwards.

In the report on the first night's observations in 1924 (1, p. 779) the types of behaviour shown by the different species were grouped under the following four headings :-

1. Those that definitely migrated to the surface at night from the deeper layers in which they dwelt by day, showing a very large increase in numbers on the surface with a corresponding decrease in the deeper layers. 
2. Those that did not show a definite migration to the surface at night, but merely extended their distribution into the surface layers, which they avoided by day. In this case a diminution in numbers was shown at the region of maximum intensity in the daytime, so that the distribution from surface to deeper layers was more or less uniform.

3. Those forms whose daytime distribution altered little or not at all at night.

4. Those that showed a movement upwards from the bottom, appearing in large numbers at night at a level about 10 fathoms from the bottom.

Actually it seems probable now that these groups cannot be separated, but that one merges into the other and a complete gradation can be obtained in the different types of behaviour, depending largely on the depths at which the animals are living in the daylight and the rates at which they can swim upward. In the present paper the figures giving the diagrams of vertical distribution for the different species (Figs. 1-7, pp. 776 and 782) have been arranged in order to give more or less a complete gradation from a species such as Leuckartiara (=Turris) which migrates rapidly to the surface at dusk, to Mysids and other bottom-living animals which have time only to reach the layers up to 20 metres below the surface. Good examples also are given showing how in one group of animals differences in activity will produce different behaviour atnight. The diagram in Figure 6, for instance, shows that Mysids, chiefly Leptomysis gracilis, do not apparently have time during the night to migrate in numbers above 20 metres, whereas Anchialus agilis, as its name implies, is able rapidly to migrate right to the surface in considerable numbers (Fig. 5). A comparison of these figures with Figures 5 and 6 in the previous publication (1) shows that in 1924 these two species of Mysids showed exactly the same difference in their behaviour, the diagrams for the same species being almost identical. Figure 7, p. 782, shows the behaviour of two Cumacean species* at night; Diastylis rostrata, like Leptomysis, did not appear in numbers above 20 metres, but Bodotria scorpioides, like Anchialus, migrated right to the surface. It is interesting to record as on a previous occasion $(\mathbf{1}$, p. 797$)$ that many of the Diastylis taken above the bottom at night were females. The young swimming crabs also were able to mount right to the surface in the dark, whereas the young of Pandalina brevirostris, like Leptomysis, could not migrate in numbers above

* I am greatly indebted to Dr. W. T. Calman, F.R.S., and Dr. Isabella Gordon for the identification of these two species as D. laevis Norman $(=D$. rostrata (Goodsir) in "Plymouth Marine Fauna") and Bodotria (=Cuma) scorpioides (Montagu) (=C. edwardsi of Sars', "Crustacea of Norway"). B. scorpioides is recorded for the first time at Plymouth. 
the 20-metre level. Many other examples can also be seen, such as Themisto gracilipes as opposed to bottom amphipods. It is possible even that some species, e.g. perhaps Bougainvillea and Steenstrupia, which show no marked change in their distribution during the night hours, are prevented from doing so by their inability to swim quickly.

A study of pages 771-775, in which the results for the three years are compared, shows that for a great number of species almost identical types of behaviour were shown for all three years. For other species differences were shown, the animals behaving differently in one year from the other two. In no case did a species behave in a different manner in all three years. It is noteworthy that the majority of species showing the same type of behaviour in all three years were those which lived deep down or very near the bottom in the daytime, and whose depth is limited by that of the bottom. For animals of this class power of movement may be said to be almost more of a conditioning factor in their type of distribution at night than such factors as light intensity. For animals living nearer the surface, however, daylight may control the ultimate night distribution more, in that it affects the daytime distribution of the animals, which are not so limited in the depths to which they descend as are those which normally live very near the bottom. It is therefore more likely that differences in behaviour will be shown by those animals living nearer the surface in the daytime (see 4, p. 404).

Differences in vertical distribution due to season also may affect the behaviour of the animals; Tomopteris, for instance, in June lives very near the bottom in the daytime and its diurnal behaviour consequently appears very different from that shown in July when they are well up in the water during daylight.

At the same time the different animals are not all quite consistent in their behaviour. For instance, it has been shown that Sagitta in 1925 $(4$, p. 404) was living very near the bottom in the daytime, possibly being forced down by strong light owing to the clearness of the water, whereas in 1924 and 1926 Sagitta was well up in the water in the daytime. There is no evidence, however, that some of the other animals were affected to so marked a degree. Such phenomena can only be understood when we have far more observations carried out in greater detail.

A comparison of the four nights shows also that more of the deep-living animals reached the layers up to the surface in the nights in June, 1925, than they did on either of the nights in July, 1924, or June, 1926. It seems possible that owing to the scarcity of plankton animals on the nights in 1925 their passage upward was less impeded by obstructing animals. The presence of other animals in large numbers must in itself cause modification of the behaviour to be expected of an animal in perfectly uninhabited water. Both avoiding reactions and feeding reactions must 
tend to divert an animal from its pure responses to physical and chemical environmental stimuli.

\section{Summary of Observations on Four Nights.}

Steenstrupia nutans. * 1924. "No marked vertical movements at night": numbers rather low.

1925. First night-numbers rather low.

Second night: "in the dark there had been a decided movement into the layers above 20 metres ": did not extend in numbers much above $12 \mathrm{~m}$.

1926. No marked vertical movement at night; slightly higher in water at dawn.

Leuckartiara octona.† 1924. "By 9 p.m. the majority were caught above a depth of 10 metres, and at midnight they were taken in greatest numbers right at the surface."

1925. "On both nights - but more markedly on the first-there seems to have been an active migration to the surface itself at dusk, followed by a downward movement at night in the dark and a further upward migration at dawn."

1926. Although the numbers rather point to encountering horizontal swarms there was a marked migration to surface at dusk, followed by a descent in the dark and a further upward migration at dawn. The medusæ remained high in the water the following day.

Obelia sp. 1924. "It cannot be said that there was any marked movement towards the surface at night."

1925. "The catches of Obelia were very small, and appear to indicate little co-ordinated movement."

1926. Entirely absent at night : no indication of movement at dusk.

Phialidium sp. 1924. "showed no signs of being affected by changes in light intensity."

1925. "There appear to be definite indications of an upward movement on the part of these medusæ at night."

1926. No very marked movement at night shown.

Cosmetira pilosella. 1924. " "it would seem that here is shown a definite migration to the surface at night." Numbers rather low : present at surface at dusk.

1925. On both nights were evenly distributed from surface downwards in the dark : no movement at dusk.

1926. Same as 1925 .

* All specific names used are those adopted in the Plymouth Marine Fauna, 2nd edition. 1931. Previously recorded as S. rubra. $\quad+=$ Turris pileata in previous papers. 
Saphenia gracilis. 1924. "Present at the surface both at 9 p.m. and at midnight, and absent from there at other times." Numbers low.

1925. "the impression gained is that in its diurnal behaviour Saphenia resembled Cosmetira, except that in the daytime it went possibly deeper."

1926. Resembled Cosmetira in its behaviour, except fewer at surface itself.

Tomopteris helgolandica. 1924. Present in numbers right at the surface at dusk and at night, but they were already high in the water in the daytime, when the region of maximum abundance was at about 20 metres.

1925. On both nights Tomopteris appeared in numbers on the upper layers at dark and dawn, being probably very near the bottom in the daylight.

1926. Very similar behaviour to 1925 , the majority probably living very near the bottom in the daytime.

Sagitta sp. These have been dealt with separately in another publication (4), the populations having been divided up into different size groups. There was, however, a very definite difference in the behaviour in 1925 from that shown in 1924 and in 1926. This would seem to be explained by the fact that in the daytime in 1925 the Sagitta were almost on the bottom, whereas in the other two years they were well up in the water layers in daylight.

Calanus finmarchicus. 1924. A definite migration to the surface at dusk, followed by an even distribution from the surface downwards in the dark.

1925. "By dusk there had been a marked upward movement in the water. . . . In the dark they were mostly distributed between the surface and 25 metres. The movements . . . were not as marked on the second night as on the first."

1926. Adult females: Slight upward movement at dusk followed by fairly even distribution from surface downwards in the dark. Larger concentration at 5 metres at dawn.

Adult males: Being lower in the water in daytime than the females hardly any had reached the surface by dusk, and the majority were still deep in the water at night.

Candacia armata. 1924. Definite migration to the surface at dusk, followed by fairly even distribution at night.

1925. Definite migration to the surface in the dark, but not at dusk, as the majority were living very deep down in the daytime.

1926. Same as 1925 . 
Mysids: Mostly Leptomysis gracilis.

1924. Appeared in larger numbers at night, but majority did not rise above 20 metres.

1925. Similar behaviour to 1924 but rather more taken in surface layers.

1926. Behaviour same as in 1924 .

Anchialus agilis. 1924. "Unlike the other Mysids, which never rose much above 20 metres from the bottom, this form exhibited a very sudden migration towards midnight right to the surface."

1925. Similar to 1924 though fewer at surface and more evenly distributed.

1926. Behaviour same as in 1924 .

Cumaceans. Showed the same type of behaviour in all three years, appearing only in upper layers at night. It was noticeable that the Diastylis species, probably $D$. rostrata, were not caught in numbers above $20 \mathrm{~m}$. at night, but that Bodotria sp. were able to reach the surface (see page 769).

Themisto gracilipes.* 1924. "A marked migration to the surface at midnight."

1925. Very rare.

1926. Same behaviour as 1924 .

A pherusa sp. 1924. "Exhibited no marked movement at night."

1925. Marked movement on both nights, being evenly distributed from surface downwards.

1926. Probably same behaviour as 1925, though numbers at night rather low.

Bottom Amphipods showed same type of behaviour in all three years, appearing in upper layers at night only.

Pandalid larva. 1924. "Did not . . . show any marked change. . . . There is perhaps a slight tendency to rise at midnight, but the larvæ never appeared in numbers in the surface layers."

1925. There was a definite indication of an extension into the upper layers at night.

1926. Rather similar behaviour as in 1924 .

Crangonid larve and post-larvae. 1924. Appeared in upper layers at night, but were still most abundant below 20 metres.

1925. Same as 1924. but larger numbers extending to surface.

1926. Same as 1925 .

Phyllosoma larva. 1924. Marked movement right to surface by dusk : but entirely absent at night.

* Parathemisto oblivia in "Plymouth Marine Fauna." 
1925. Same as 1924: still present throughout upper water layers at night.

1926. Same as 1925 .

Galatheid larva. 1924. "At dusk and at midnight they tended to become more evenly distributed from the upper layers downwards, but were at no time very abundant on the surface."

1925. Upper layers filled up right to the surface at night.

1926. Same as 1925 but not so marked, as they were living higher in the water in the daytime.

Galatheid post-larva. 1924. Appeared in numbers at night in upper layers, but still most abundant below 20 metres.

1925. In numbers right to surface itself at night.

1926. In numbers right to surface itself at night.

Porcellana zoeas. 1924. " had spread out by 9.30 p.m. into all layers, and were still distributed in this manner at midnight."

1925. "The midnight behaviour on these two nights was apparently very unco-ordinated, but may possibly have been upset by the presence of swarms."

1926. Same as 1924, but more massed in upper layers in dark.

Porcellana post-larva. 1926. Similar behaviour to that of Galatheid post-larvæ, but rather slower going down at dawn.

Upogebia larva. 1924. "By 9 p.m. they were present in all layers from the surface to 30 metres. At midnight by far the majority were taken on the surface."

1925. "By dusk they were extending their distribution up to between 10 and $15 \mathrm{~m}$., and in the dark they were most abundant actually at the surface." On second night "the surface itself was not fully populated as on the previous night."

1926. By dusk many had already reached surface, and at night biggest catch was just below the surface at 4 metres.

Pagurid larva. 1924. " There was a very slight rise at midnight, but no increase in numbers at the surface."

1925. A very marked movement, the surface layers being filled from the surface downwards at night.

1926. Definite extension into surface layers at night.

Pagurid glaucothoë. 1924. " At midnight they were taken on the surface, but in greatest numbers at 20 and 30 metres."

1925. "In the dark they moved up into the upper water layers as far as the surface itself, though the largest catches were still below $25 \mathrm{~m}$."

1926. Same behaviour as 1924 . 
Crab zoeas (mostly Portunids). 1924. "Extending into the upper layers and surface at dusk and midnight."

1925. "A considerable increase in numbers in the layers above 15 to $20 \mathrm{~m}$. on both nights, an increase which was pronounced also at the surface itself."

1926. Same as 1924 .

Crab megalopas (mostly Portunids). 1924. "At midnight . . . appeared on the surface in large numbers, being distributed from top to bottom."

1925. A marked movement to the surface in the dark on both nights.

1926. A marked movement to the surface in the dark. Although at the surface in the daylight they were mostly below 10 to 15 metres at dusk.

\section{SUMMARY.}

1. Details are given of the results of a series of hauls with the 2-metre stramin ring-trawl fished at six different depths in daylight, at dusk, in the dark, at dawn and again in daylight on June 3rd-4th, 1926.

2. A comparison is given of the results obtained on the four nights July 15-16th, 1924; June 17-18-19th, 1925, and June 3rd-4th, 1926.

3. The importance is stressed of the effects on the type of behaviour shown by any animal produced by the depth at which it is living in the daylight and the speed at which it can swim upwards.

\section{REFERENCES.}

1. Russell, F. S. The Vertical Distribution of Marine Macroplankton. An Observation on Diurnal Changes. Journ. Mar. Biol. Assoc., N.S., Vol. XIII, No. 4, p. 769, 1925.

2. - - The Vertical Distribution of Marine Macroplankton. VI. Further Observations on Diurnal Changes. Ibid. Vol. XV, No. 1, p. $81,1928$.

3. - The Vertical Distribution of Marine Macroplankton. VIII. Further Observations on the Diurnal Behaviour of the Pelagic Young of Teleostean Fishes in the Plymouth Area. Ibid. Vol. XV, No. 3, p. 829, 1928.

4. - . The Vertical Distribution of Marine Macroplankton. X. Notes on the Behaviour of Sagitta in the Plymouth Area. Ibid. Vol. XVII, No. 2, p. 391, 1931. 


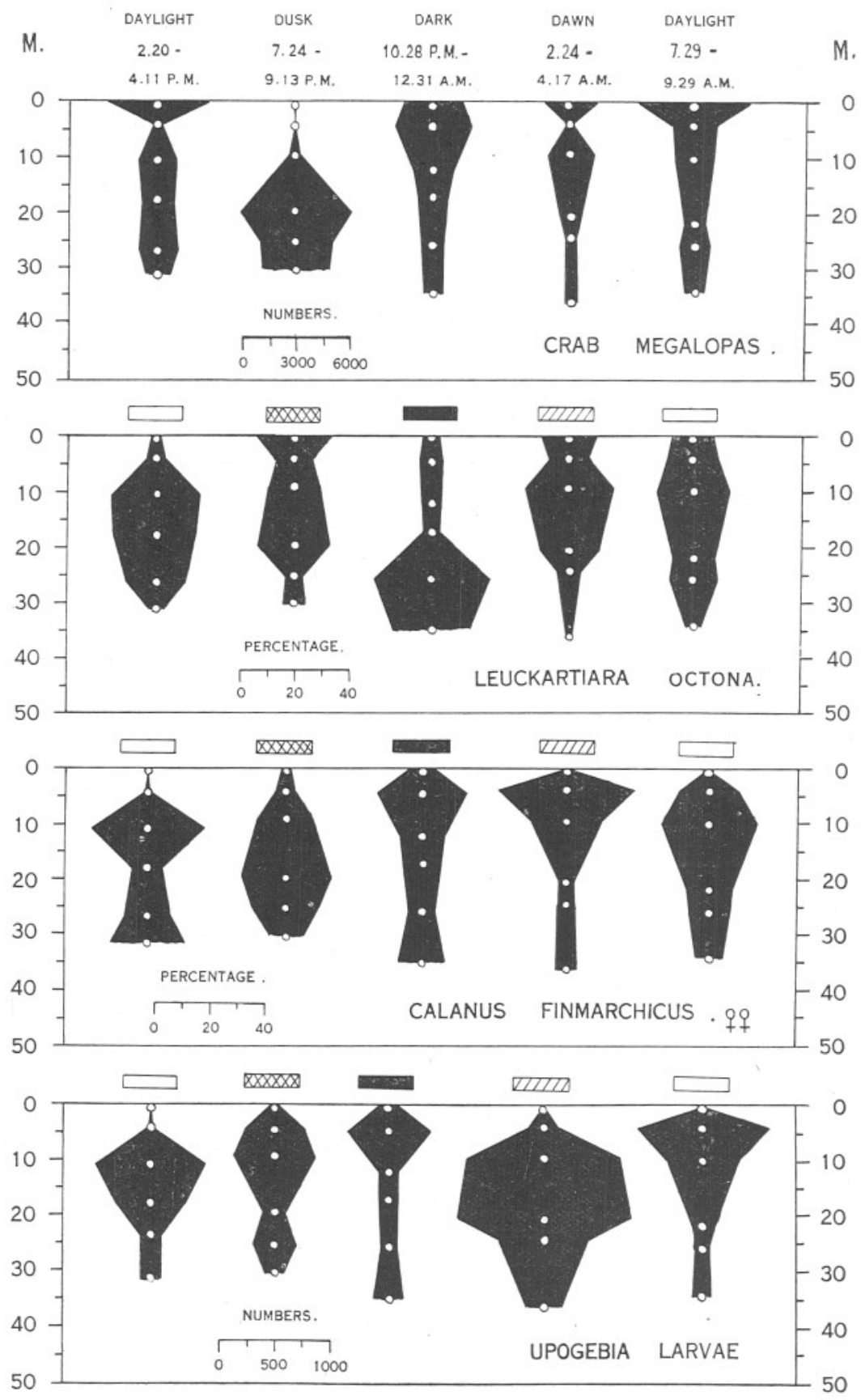

FIG. 1.-The vertical distribution of Crab megalopas (mostly Portunids), Leuckartiara octona (=Turris), Calanus finmarchicus adult females, and Upogebia larvæ at the times shown on June 3rd-4th, 1926. The plain, cross-hatched, black, and shaded rectangles represent " daylight," dusk," "dark," and "dawn " respectively. The white spots and black circles indicate the average depths at which hauls were taken. 


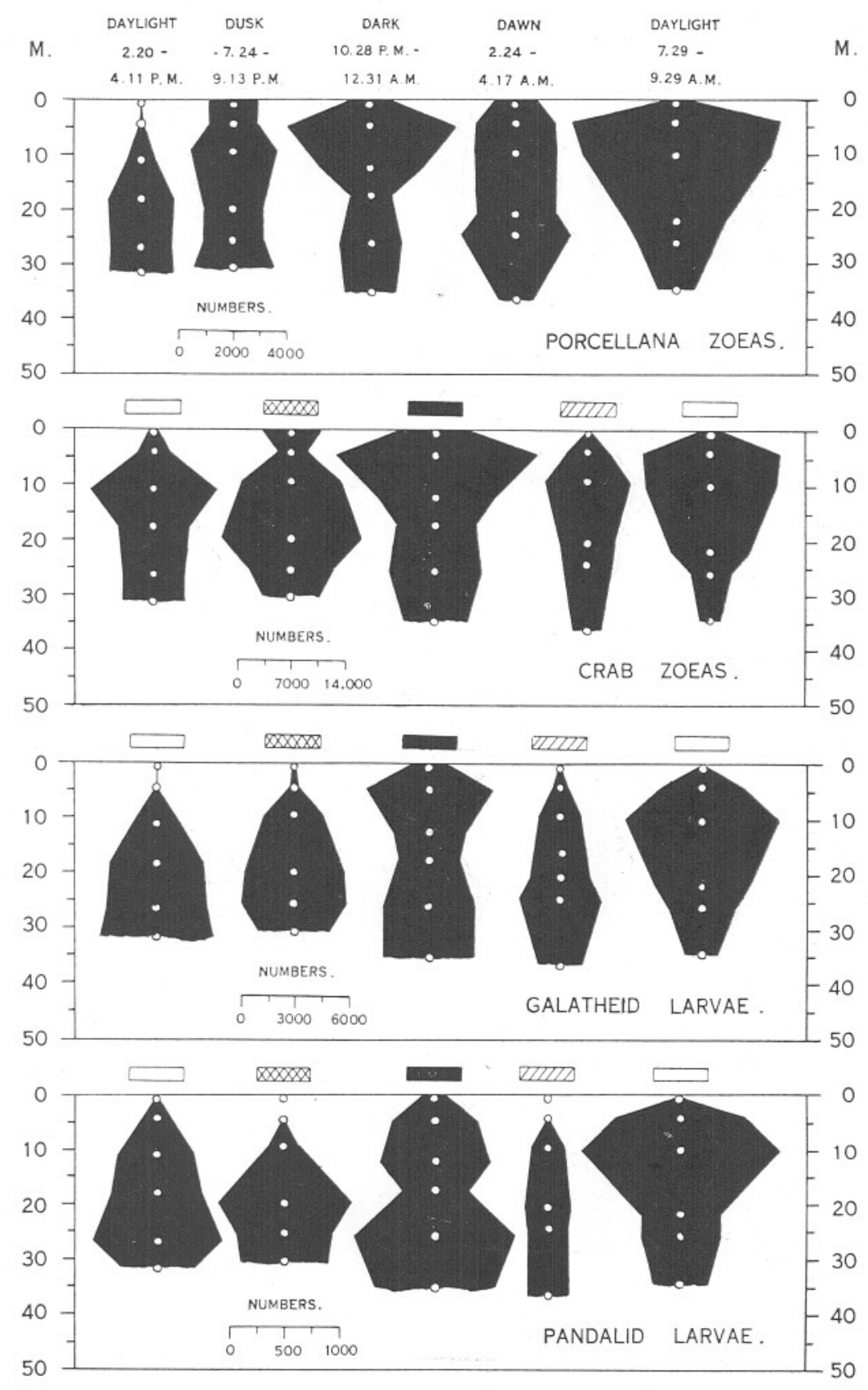

FIG. 2.-The vertical distribution of Porcellana zoeas, Crab zoeas (mostly Portunids), Galatheid larvæ, and Pandalid larvæ, at the times shown on June 3rd-4th, 1926. The plain, cross-hatched, black, and shaded rectangles represent " daylight," "dusk," "dark," and "dawn " respectively. The white spots and black circles indicate the average depths at which hauls were taken.

NEW SERIES.-VOL. XVII. NO. 3. OCTOBER, 1931. 


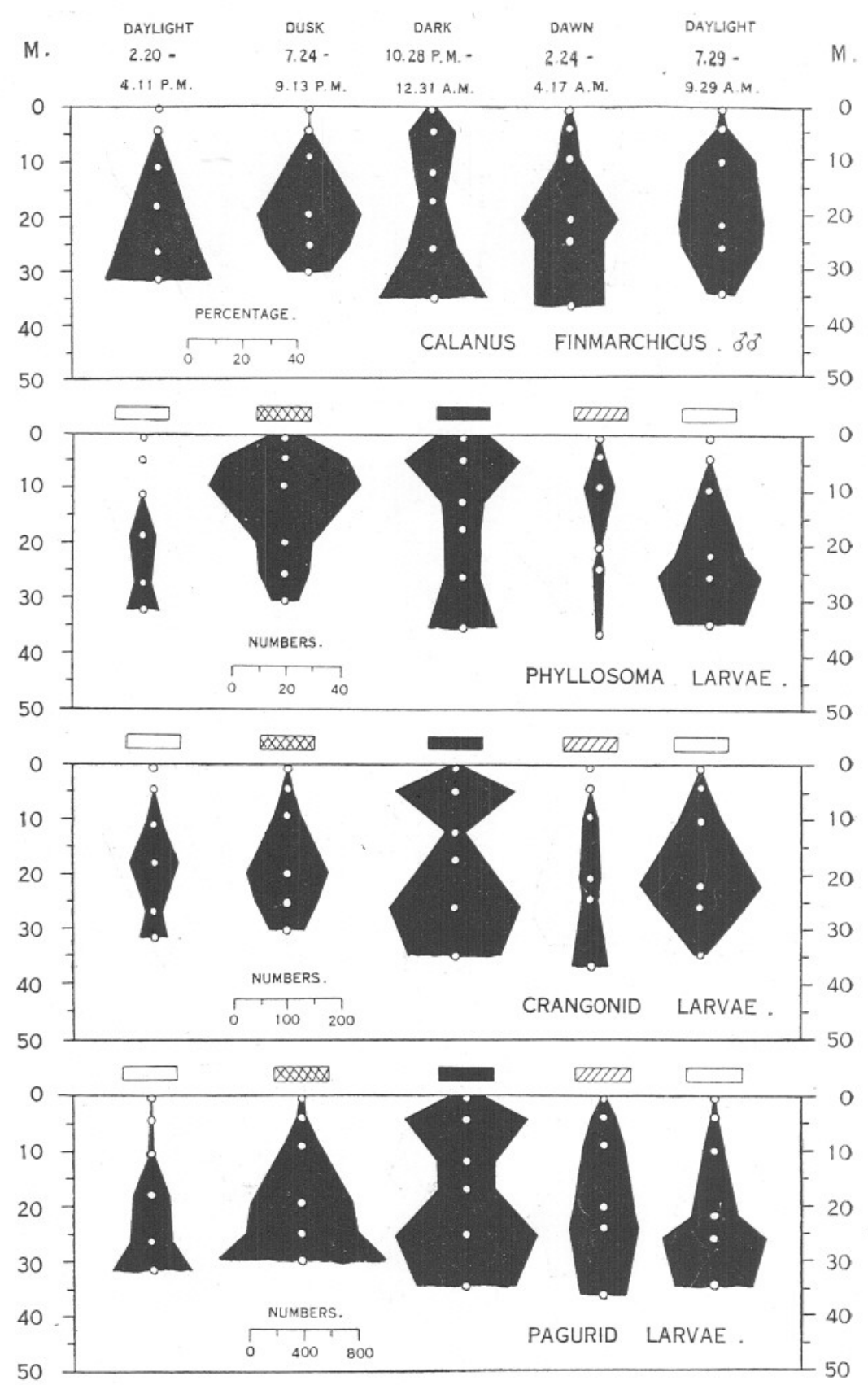

FIG. 3.-The vertical distribution of Calanus finmarchicus adult males, Phyllosoma. larvæ, Crangonid larvæ, and Pagurid larvæ at the times shown on June 3rd-4th, 1926. The plain, cross-hatched, black, and shaded rectangles represent " daylight," " dusk," "dark," and "dawn " respectively. The white spots and black circles indicate the average depths at which hauls were taken. 


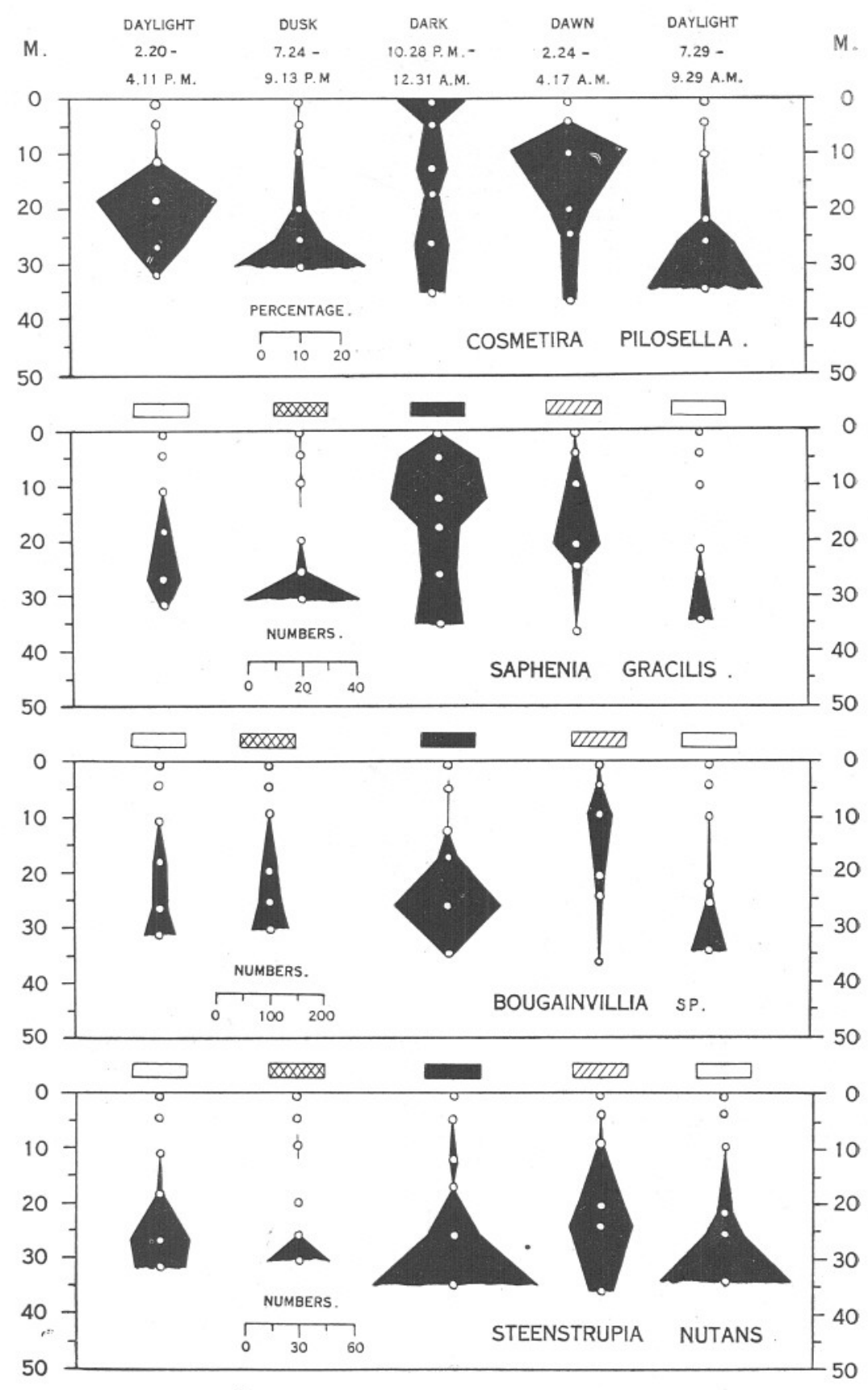

Frg. 4.-The vertical distribution of Cosmetira pilosella, Saphenia gracilis, Bougainvillea sp., and Steenstrupia nutans at the times shown on June 3rd-4th, 1926. The plain, cross-hatched, black, and shaded rectangles represent " daylight," " dusk," " dark," and "dawn" respectively. The white spots and black circles indicate the average depths at which hauls were taken. 


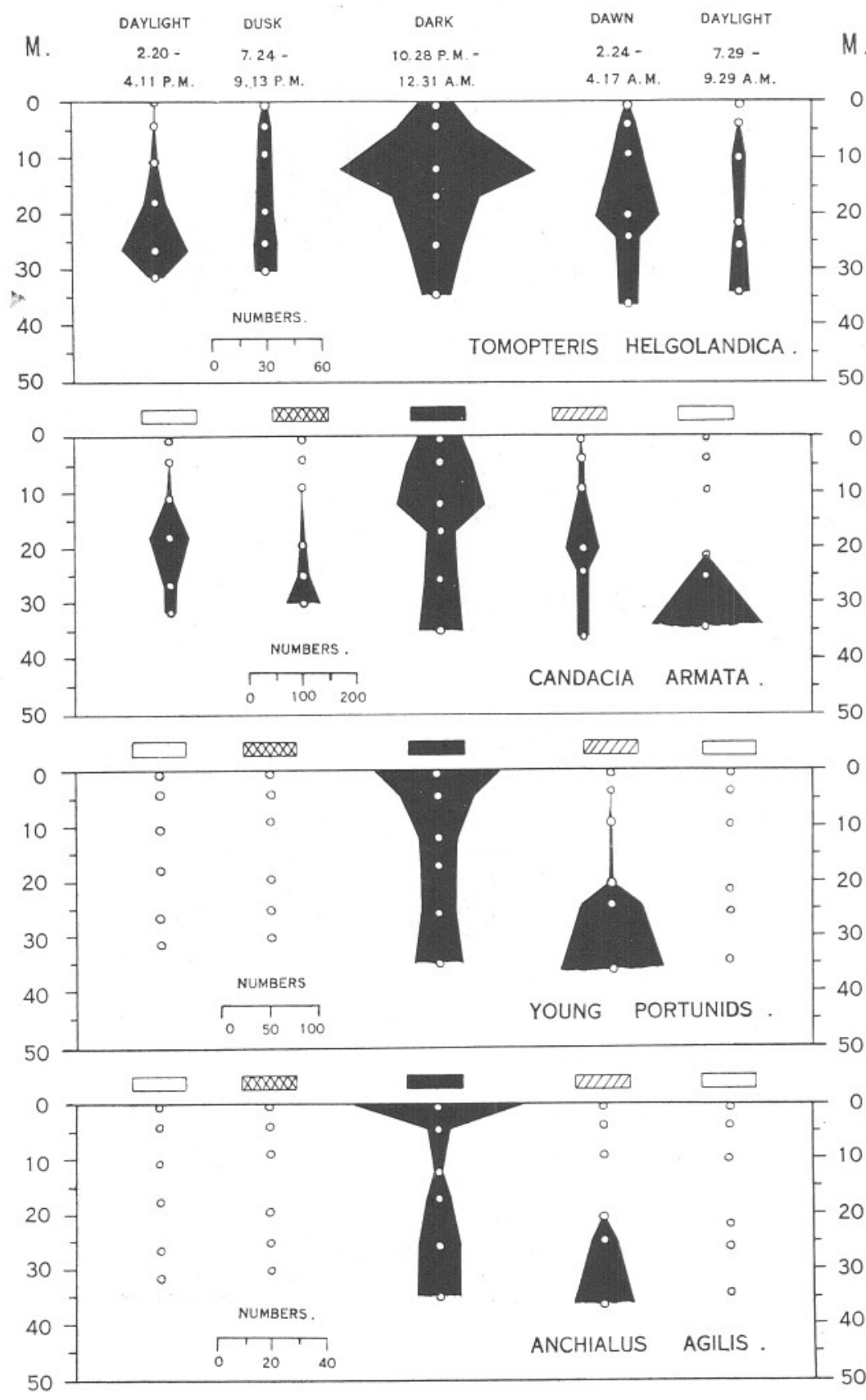

FIG. 5.-The vertical distribution of Tomopteris helgolandica, Candacia armata, Young Portunids, and Anchialus agilis at the times shown on June 3rd-4th, 1926. The plain, cross-hatched, black, and shaded rectangles represent " daylight," " dusk," " dark," and "dawn" respectively. The white spots and black circles indicate the average depths at which hauls were taken. 


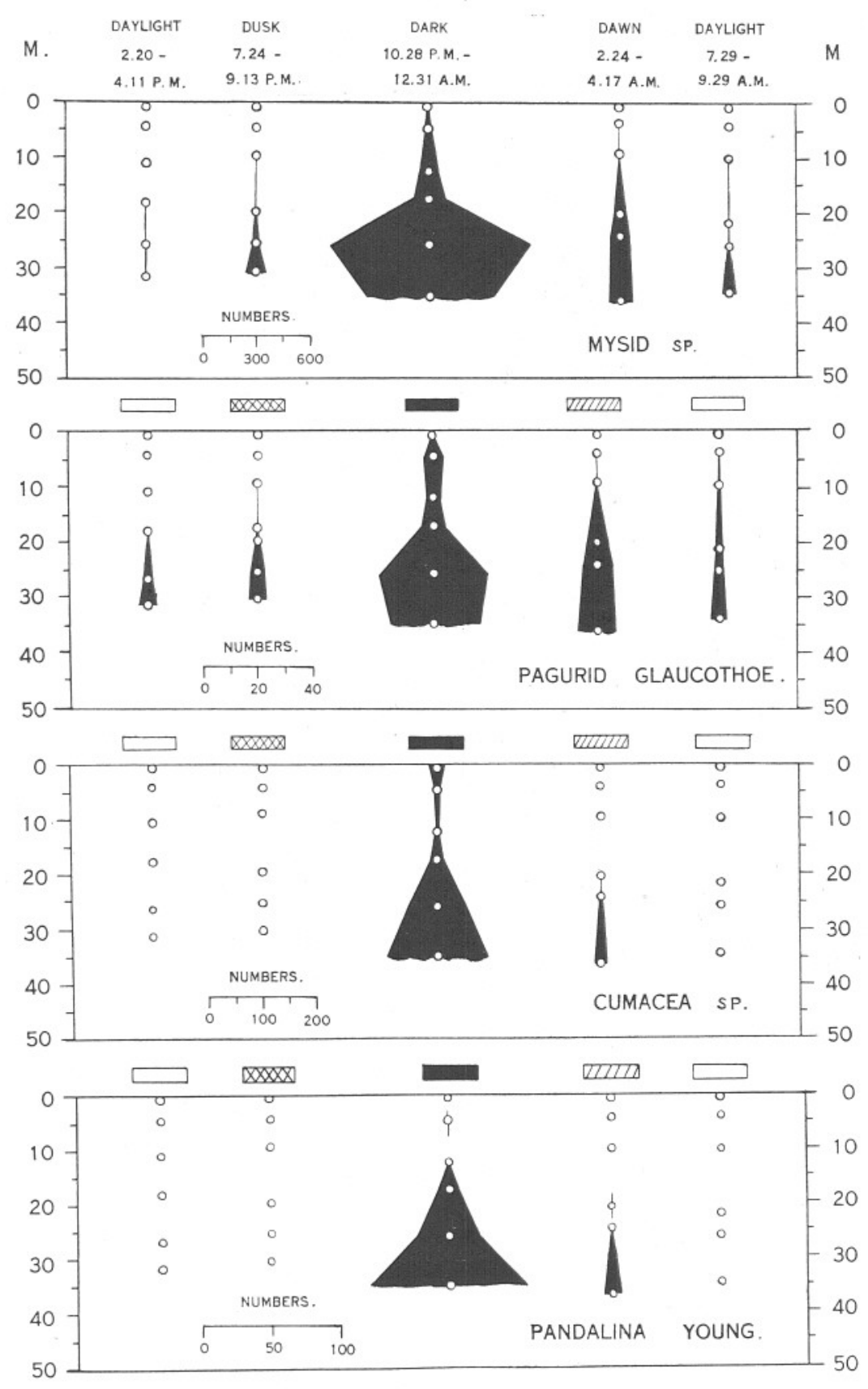

FIG. 6.-The vertical distribution of Mysids (chiefly Leptomysis gracilis), Pagurid glaucothoë, Cumacea, and young Pandalina brevirostris at the times shown on June 3rd4th, 1926. The plain, cross-hatched, black, and shaded rectangles represent "daylight," "dusk," "dark," and "dawn " respectively. The white spots and black circles indicate the average depths at which hauls were taken. 
M.

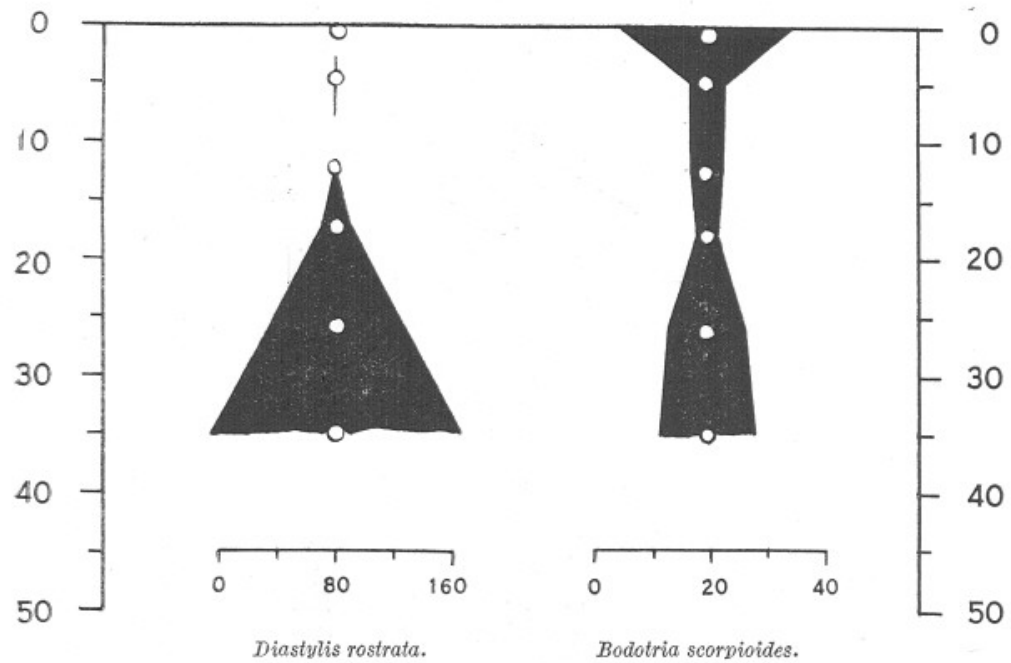

FIG. 7.-The vertical distribution of Diastylis rostrata (left) and Bodotria scorpioides (right) in the dark on June 3rd-4th, 1926. The white spots and black circles indicate the average depths at which hauls were taken. The scales give the actual numbers caught.

\section{NOTES ON TABLE I.}

\section{Series 1 .}

Leuckartiara octona. At surface and $4.25 \mathrm{~m}$. in first daylight series these were all small medusæ; the larger medusæ being in the deeper layers.

Tomopteris helgolandica from surface, $4 \cdot 25$ and $10 \cdot 75 \mathrm{~m}$., were all in a damaged state. Nyctiphanes. Series one-all juvenile.

Mysids were very small stages.

\section{SERIES 2.}

Crab zoeas. Surface and $4 \cdot 4 \mathrm{~m}$. Mostly very small specimens.

Galatheid 1. Surface, small.

Porcellana zoea. Surface, small.

Pandalid l. $4.4 \mathrm{~m}$. Very small.

Crangonid 1. $4.4 \mathrm{~m}$. Very small.

Hyperiid at surface $=H$. alba .

Nyctiphanes. All juvenile.

SERIES 3.

Leuckartiara octona. Surface. Small.

$4.6 \mathrm{~m}$. Half small.

$12 \cdot 3 \mathrm{~m}$. Most small.

$11 \mathrm{~m}$. Small.

rest $=$ some small.

Young Portunids. Thirty-eight examined at $25 \cdot 9 \mathrm{~m}$. by R. Palmer $=$ all $P$. depurator.

Young crangons up to $15 \mathrm{~mm}$. long. At 25.9 there were two and at $35 \mathrm{~m}$. three Philoceras bispinosus in berry 12 and $15 \mathrm{~mm}$. long.

Series 5

Leuckartiara octona. Surface to $10 \mathrm{~m}$. Many small: larger deeper. 
TABLE I. Ring-Trawl Catches. June 3RD-4TH, 1926.

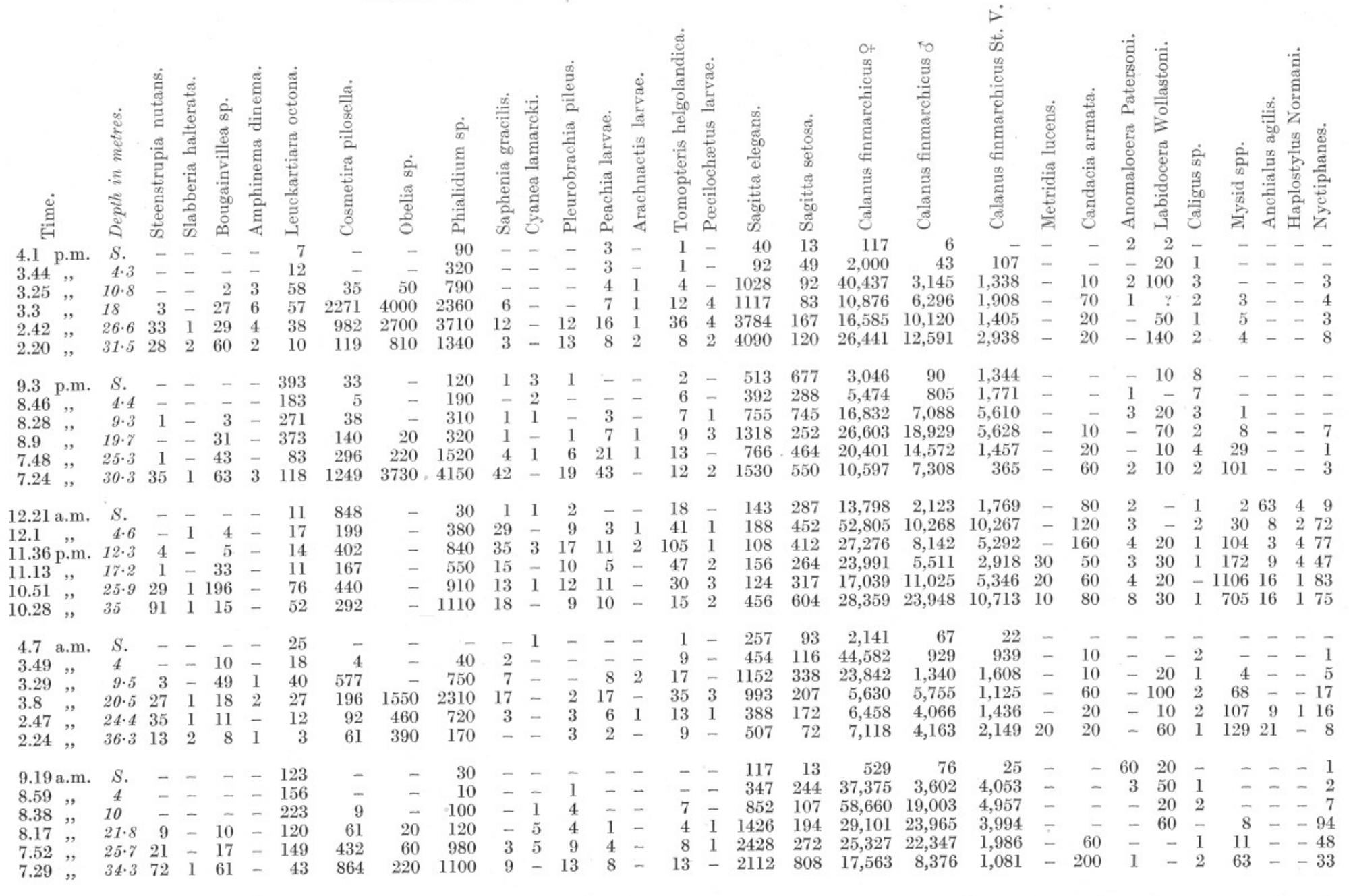




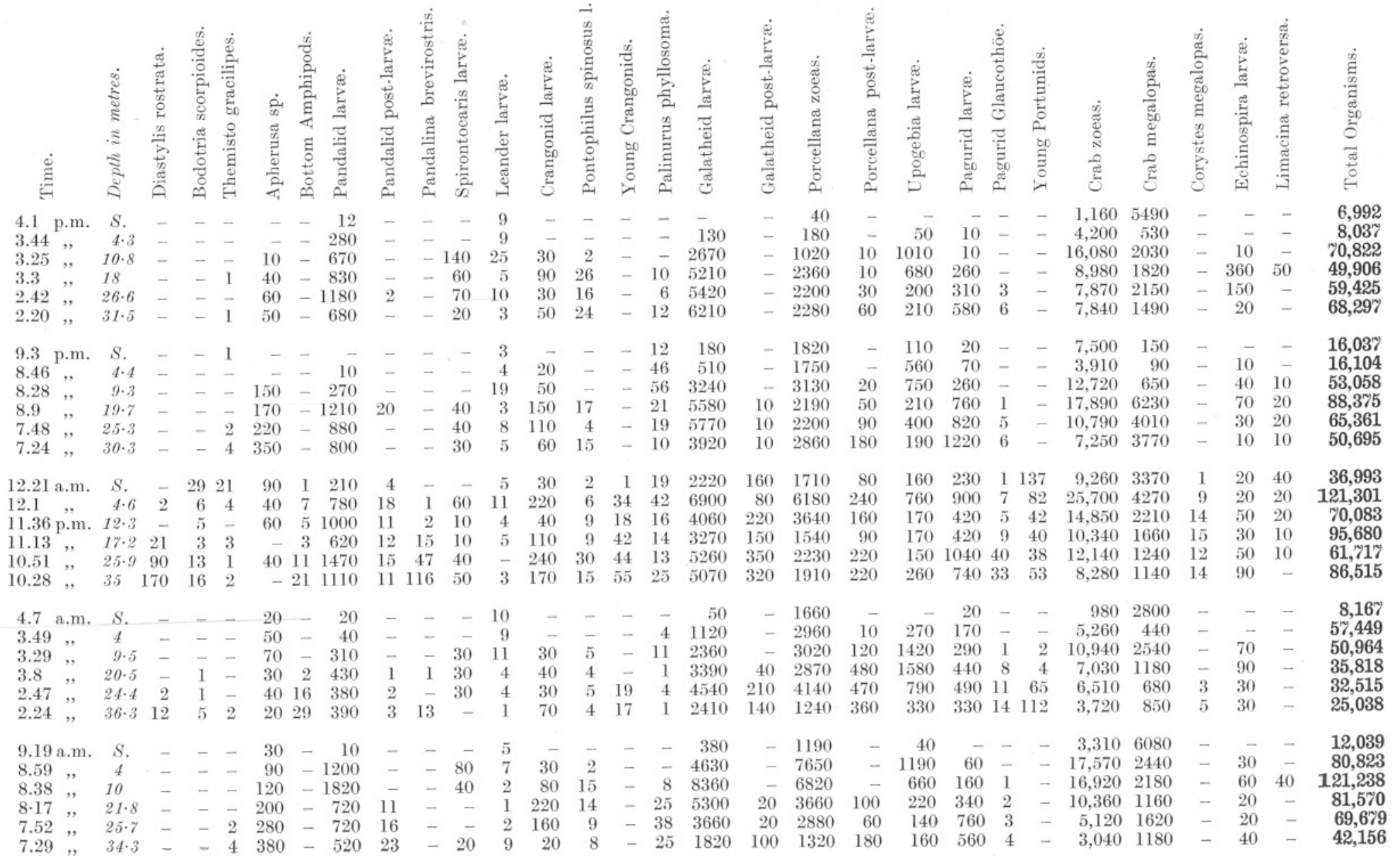

